\title{
PENGARUH PERBANDINGAN WAKTU TANGKAP PANCING TONDA DI PERAIRAN SAUMLAKI KABUPATEN KEPULAUAN TANIMBAR
}

\section{COMPARISON OF TRILL FISHING TIME IN SAUMLAKI WATERS TANIMBAR ISLANDS REGENCY}

\author{
Deni Sarianto $^{1 *}$, Djalaludin Kemhay ${ }^{2}$, Kadi Istrianto ${ }^{3}$, Restu Widayaka ${ }^{1}$, \\ Adnal Yeka ${ }^{1}$, Reny Wulandari \\ ${ }^{1}$ Dosen Politeknik Kelautan dan Perikanan Pariaman \\ ${ }^{2}$ Dosen Politeknik Kelautan dan Perikanan Maluku \\ ${ }^{3}$ Dosen Politeknik Kelautan dan Perikanan Karawang \\ *email:Denisarianto45@gmail.com
}

\begin{abstract}
ABSTRAK
Penelitian bertujuan untuk melihat hasil tangkapan pancing tonda berdasarkan waktu penangkapan. Penelitian ini dilakukan pada bulan Agustus hingga November 2019 di Perairan Saumlaki dengan menggunakan metode survei untuk mendapatkan data tangkapan dan waktu operasi. Data penelitian kemudian dianalisis dengan GT kapal menurut PM Perhubungan tahun 2013, mengenai pengukuran kapal, CPUE, formula sturges dan chi-kuadrat dengan ketelitian 0.05 dan 0.01 , serta perbandingan hasil tangkapan untuk menjelaskan hasil penelitian grafis. Hasil penelitian menunjukkan bahwa ukuran kapal 8 GT, panjang total hasil tangkapan ikan cakalang pancing tonda $30-75 \mathrm{~cm}$ dan tuna madidihang $34-74 \mathrm{~cm}$, serta perbedaan waktu penangkapan antara pagi dan sore cenderung mengalami perbedaan dan berpengaruh pada hasil tangkapan, di mana waktu tangkap terbaik di pagi hari. Hal ini diperkuat lagi dengan analisis chi-kuadrat dengan $X_{\text {hitung }}^{2}>X^{2}$ tabel untuk jumlah ekor ikan cakalang, jumlah ekor ikan tuna madidihang, jumlah ekor ikan cakalang dan tuna madidihang dan berat ikan cakalang, berat ikan tuna madidihang, berat ikan cakalang dan tuna madidihang. Namun pada CPUE, CPUE jumlah ikan cakalang, CPUE jumlah ikan tuna madidihang, CPUE jumlah ikan cakalang dan tuna madidihang dan CPUE berat ikan cakalang, CPUE berat ikan tuna madidihang memiliki nilai $X^{2}{ }_{\text {hitung }}<X^{2}$ tabel sedangkan pada CPUE berat ikan cakalang dan tuna madidihang memiliki nilai nilai $X^{2}$ hitung $>X^{2}{ }_{\text {tabel }}$.
\end{abstract}

Kata kunci: Saumlaki, pancing tonda, waktu tangkap

\begin{abstract}
Research with the to see the time of capture of the troll fishing catches. This research wasconducted from Agustus to November 2019 at Saumlaki Sea using a survey method to obtain catch data and operating time. The research data were then analyzed by ship GT according to PM of Transportation in 2013, regarding ship measurements, CPUE, formula sturges and chisquared with accuracy of 0,05 and 0,01, as well as catch comparisons to explain the results in graphical from. The results showed that the size of the 8 GT boat, the total length of the catches of trolling line fish skipjack tuna 30-75 cm and yellowfin $34-74 \mathrm{~cm}$, as well as the difference in fishing time between morning and evening tended to have an influence on the cath where the best catch time in the morning. This in further strengthened by the the chi-square analysis with $X^{2}$ count $>X^{2}$ table for the number of tuna tails, number of yellowfin tuna, number of skipjack and yellowfin tuna and tuna weight, yellowfin tuna weight, fish weight, skipjack and yellowfin tuna. But for CPUE, CPUE for skipjack tuna, CPUE for yellowfin tuna, CPUE for skipjack and
\end{abstract}


yellowfin tuna and CPUE for skipjack tuna, CPUE weight for yellowfin tuna has a value of $X^{2}$ count $\left\langle X^{2}\right.$ table while on CPUE the weight of skipjack tuna and yellowfin tuna has a value of $X^{2}$ count $>X^{2}$ table.

Keywords: Saumlaki Sea, Trolling line, Time of Catching

\section{PENDAHULUAN}

Potensi Perikanan yang ada di Perairan Maluku dan Maluku Utara diketahui melimpah, mengingat Perairan Maluku merupakan daerah dengan kandungan klorofila-a yang tinggi, sebagai tempat berkumpulnya ikan-ikan (Sarianto, 2018).

Provinsi Maluku memiliki potensi perikanan di tiga WPP yaitu Laut Banda, Laut Seram, Laut Arafura sebesar 4,6 juta ton per tahun (32 persen) dari 12,5 juta total potensi sumberdaya. Namun potensi tersebut baru dimanfaatkan sekitar $18,5 \%$ di tahun 2019, oleh sebab itu potensi tersebut perlu dimanfaatkan secara optimal (Latuconsina, 2010). Sumber perairan dan perikanan yang begitu melimpah menjadikan Maluku salah satu fishing ground perikanan tuna terbesar di Indonesia.

Salah satu kabupaten yang memiliki potensi perikanan yang cukup besar di Provinsi Maluku adalah Kabupaten Kepulauan Tanimbar. Kabupaten ini berada pada Laut Arafura (WPP 718) dan Laut Banda (WPP 714), yang memiliki potensi besar terhadap pemanfaatan sumberdaya ikan (SDI) baik itu ikan pelagis maupun ikan demersal yang di perkirakan potensi ikan didalamnya mencapai 2,4 juta ton, pada tahun 2018 produksi dan nilai perikanan tangkap Maluku Tengara Barat/Kepulauan Tanimbar jumlanya hanya mencapai 9.425 ton dengan nilai $\mathrm{Rp} 125$ miliar (Luhur and Yusuf, 2017).

Aktivitas penangkapan ikan di Kabupaten Kepulauan Tanimbar dilakukan dengan mengunakan berbagai jenis alat tangkap, diantaranya alat tangkap purse seine, jaring insang, pancing tonda, pancing ulur dan pancing lainya. Pancing Tonda merupakan salah satu alat tangkap yang dominan untuk jenis alat tangkap pancing yang digunakan nelayan di Saumlaki
Kabupaten Kepulauan Tanimbar dalam melakukan aktivitas penangkapan ikan. Proses penangkapan mengunakan pancing tonda yang digunakan oleh nelayan Saumlaki biasanya 1-3 hari dalam melakukan trip penangkapan.

Dibandingkan dengan alat-alat penangkapan ikan lainya, Alat pancing tonda pada prinsipnya tidak banyak mengalami perubahan. Karena hanya meletakan umpan pada mata pancing diberi tali, setelah umpan dimakan maka mata pancing juga akan termakan oleh ikan dan dengan tali nelayan dapat menarik ikan ke kapal. Secara teknisnya banyak mengalami kemajuan, misalnya benang yang dipakai berwarna sedemikian rupa sehingga tidak tampak dalam air, umpan diberi bau-bauan sehingga dapat memberikan rangsangan untuk dimakan, bentuknya diolah sedemikian rupa sehingga menyerupai umpan yang umum digemari oleh ikan yang menjadi tujuan penangkapan secara alami.

Oleh karena itu penulis tertarik untuk melakukan penelitian tentang "perbandingan waktu tangkap pancing tonda di perairan Saumlaki Kabupaten Kepulauan Tanimbar". Dengan tujuan mendeskripsikan teknologi penangkapan ikan dengan pancing tonda, serta membandingkan hasil tangkapan pancing tonda berdasarkan waktu tangkap pagi dan sore hari.

\section{METODOLOGI}

Pada Penelitian ini, pengambilan data dilakukan pada Bulan Agustus sampai November 2019, di Perairan Saumlaki Kabupaten Kepulauan Tanimbar, dengan mengikuti secara langsung proses penangkapan alat tangkap pancing tonda selama 10 trip penangkapan di Perairan Saumlaki. Peta lokasi penelitian dapat dilihat pada Gambar 1. 


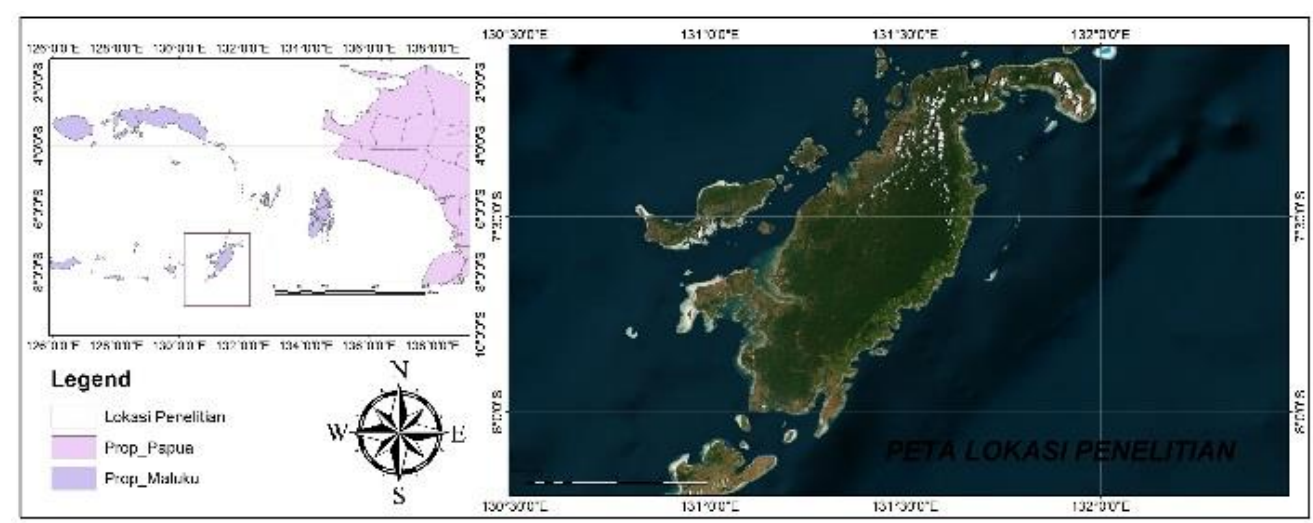

Gambar 1. Lokasi Peta Penelitian

Data yang dikumpulkan dalam penelitian ini berupa data primer dan data sekunder.

\section{1) Data Primer}

Data primer adalah data yang diperoleh atau dikumpulkan oleh peneliti secara langsung dari sumbernya. Data primer disebut juga sebagai data asli atau data baru yang memiliki sifat up to date. Untuk mendapat data primer, peneliti harus mengumpulkan secara langsung (Hamdi and Bahruddin, 2015).

Data tersebut diperoleh secara langsung serta partisipasi aktif, dengan melakukan percobaan penangkapan ikan menggunakan pancing tonda. Data kapal penangkap ikan dan alat penangkap ikan dengan pancing tonda di Saumlaki diperoleh langsung di lapangan. Kapal penangkap ikan diukur panjang total (LOA), lebar (L) dan tinggi (T) agar dapat diperhitungkan GTnya. Alat penangkapan ikan diukur dan dideskripsikan sesuai dengan kaidah-kaidah dalam teknologi penangkapan ikan atau teknologi alat penangkap ikan.

Percobahan penangkapan ikan dilakukan pada waktu pagi dan siang sampai sore hari. Pada waktu pagi, percobaan penangkapan ikan dilakukan pada pukul 05:00 WIT hingga 10:00 WIT. dan pada siang sampai sore hari pada pukul 13:00 WIT hingga 18:00 WIT. Serta penggunaan umpan juga dicatat setiap kali percobaan penangkapan ikan.

Setiap percobaan penangkapan dengan pancing tonda akan di data lama (durasi) pemancingan yaitu lama waktu pada saat alat tangkap di setting hingga pada saat hauling dengan menggunakan stop watch. Hasil tangkapan diukur panjang total dan ditimbang beratnya. Ikan hasil tangkapan juga didokumentasikan dan diidentifikasi jenisnya.

Lokasi penangkapan ikan yaitu daerah penangkapan ikan dengan pancing tonda, akan ditentukan posisinya dengan mengunakan GPS. Daerah penangkapan ikan dideskripsikan berdasarkan pengamatan visual, setiap kali percobahan penangkapan (trip penangkapan) dengan pancig tonda.

2) Data sekunder

Data sekunder diperoleh melalui kajian pustaka dan laporan dari pihak-pihak lain yang berhubungan dengan penangkapan pancing tonda. (Martono, 2010)

\section{METODE ANALISIS DATA}

Data yang diperoleh, dianalisis sesuai dengan tujuan penelitiaan sebagai berikut:

1) Analisis teknologi penangkapan ikan dengan pancing tonda

a. Kapal penangkapan ikan

Perhitungan GT kapal sesuai PM Perhubungan Nomor 8 Tahun 2013 dengan Rumus :

$$
\mathrm{GT}=0,25 \times \mathrm{V}
$$

\section{Keterangan:}

$0,25=$ Merupakan koifisien $\mathrm{K}_{1}$

$\mathrm{V}=$ Jumlah volume ruangan di bawah geladak ukur ditambah dengan jumlah volume di atas geladak yang tertutup. Rumus yang mengukur volume di bawah geladak adalah: 
Keterangan:

$$
\text { L x B x D x f }
$$

$$
\begin{aligned}
& \mathrm{L}=\text { Panjang } \\
& \mathrm{B}=\text { Lebar } \\
& \mathrm{D}=\text { Tinggi kapal } \\
& \mathrm{f}=\text { Faktor }(0,70)
\end{aligned}
$$

b. Alat penangkapan ikan

Mengukur tali utama, tali cabang, mata kail, no mata kail, dan swivel (Kili-kili).

\section{2) Analisis CPUE}

Perhitungan CPUE bertujuan untuk mengetahui perbedaan waktu tangkap dan tingkat pemanfaatan alat tangkap pancing tonda yang didasarkan atas pembagian antara total produksi (catch) dengan upaya penangkapan (effort), CPUE (Catch per Unit Effort). (Sparre and Venema, 1999) dengan rumus yang digunakan adalah:

Dimana:

$$
\text { CPUE }=\frac{\text { Catch }}{\text { Effort }}
$$

$$
\begin{aligned}
\text { CPUE }= & \text { Hasil tangkapan per upaya } \\
& \text { Penangkapan } \\
& (\mathrm{kg} /(\text { setting/hauling }) \\
\text { Catch }(\mathrm{C})= & \text { Total hasil tangkapan }(\mathrm{kg}) \\
\text { Effort }(\mathrm{E})= & \text { Total upaya penangkapan } \\
& (\text { setting/hauling })
\end{aligned}
$$

3) Analisis Sturges

Data panjang ikan ditabulasi dan dianalisis secara deskriptif untuk mengetahui perbedaan sebaran ukuran ikan antara pagi dan sore hari. Membandingkan selang kelas ukuran ikan dilakukan dengan menggunakan formula sturges $(\mathrm{K}=1+3,3 \log$ n) menurut (Sturges, 1926).

Keterangan:

$\mathrm{K}=$ selang kelas

$\mathrm{n}=$ banyaknya data

4) Analisis Chi Kuadrat $\left(X^{2}\right)$

Mengunakan uji Chi Kuadrat disebut juga Uji Goodness of Fit. Mengunakan pendekatan penjumlahan penyimpanan data observasi tiap kelas dengan nilai yang diharapkan. Uji normalitas datanya disajikan secara berkelompok. Data berbentuk nominal atau ordinal.

Ciri-ciri Distribusi Chi Kuadrat yaitu nilai selalu positif dengan $\mathrm{df}=\mathrm{k}-1$, dimana $\mathrm{k}$ adalah jumlah kategori (variabel). Jadi bentuk distribusi chi kuadrat tidak ditentukan banyaknya sampel, melainkan banyaknya derajat bebas.

Bentuk distribusi chi kuadrat menjulur positif. Semakin besar derajat bebas, semakin mendekati distribusi normal.

$$
x^{2}=\sum_{i=1}^{k} \frac{(O i-E i)^{2}}{E i}
$$

Keterangan :

Oi = frekuensi hasil pengamatan pada klasifikasi ke-i

$\mathrm{Ei}=$ frekuensi yang diharapkan pada klasifikasi ke-i

$X^{2}=$ Nilai Chi-Kuadrat

Uji normalitas dengan mengunakan Chi-kuadrat dapat dilakukan dengan langkah-langkah sebagai berikut:

1. Mencari nilai terbesar dan kecil

2. Mencari nilai rentang

3. Mencari nilai kelas

4. Mencari panjang kelas interval (i)

5. Membuat tabel distribusi frekuensi

6. Mencari rata-rata (mean)

7. Mencari simpangan baku (standar deviasi)

8. Menbuat daftar frekuensi yang diharapkan dengan cara sebagai berikut:

- Menentukan batas kelas, yaitu ujung bawah kelas interval dikurangi 0,5 dan kemudian ujung atas kelas interval ditambah 0,5

- Mencari nilai Z menggunakan batas bawah dan batas atas kelas interval dengan rumus

$$
Z=\frac{x_{i}-\bar{x}}{s}
$$

- Mencari luas 0-Z dari Tabel kurva Normal dari 0-Z dengan mengunakan $\mathrm{Z}$ hitung.

- Mencari selisih luas tiap kelas interval dengan cara mengurangkan nilai-nilai $0-Z$ tepi bawah dengan tepi atas.

9. Mencari frekuensi yang diharapkan dengan cara mengalikan luas tiap interval dengan jumlah responden 
10. Mencari Chi-Kuadrat hitung dan membandingakan nilai $X^{2}$ hitung dengan $X^{2}$ tabel

Kriteria keputusan :

Jika $X_{\text {hitung }}^{2}<X^{2}$ tabel maka $H_{0}$ diterima : $H_{1}$ ditolak.

Jika $X_{\text {hitung }}^{2}>X^{2}$ tabel maka $H_{0}$ ditolak : $H_{1}$ diterima.

Hipotesis yang digunakan yaitu:

$H_{0}$ : tidak terdapat perbedaan atau pengaruh yang signifikan waktu tangkap

$H_{1}$ : terdapat perbedaan atau pengaruh yang signifikan waktu tangkap

\section{HASIL DAN PEMBAHASAN}

\section{Teknologi Penangkapan Ikan Pancing Tonda}

\section{Kapal}

Armada penangkapan Pancing Tonda di Perairan Saumlaki pada umumnya berupa kapal motor yang bahan dasarnya dari FRP (Fiber Reinforce Plastic) dan Kayu, dengan ukuran panjang kapal 17 meter, lebar 2.80 meter, tinggi 1 meter, dan faktor kapal 0.70. Kapal ini dilengkapi mesin pengerak diesel 3 unit dengan kekuatan mesin masing-masing $28 \mathrm{PK}$, perlengkapan penting lainnya alat penentu posisi GPS dan kompas yang dapat memudahkan nelayan dalam melaut. Lamanya operasi penangkapan dalam satu kali trip adalah 2-4 hari. Es (bungkus) yang dibutuhkan 400-600 batang/ untuk ukuran kantong plastik $1 \mathrm{~kg}$, yang memegang peranan penting untuk menjaga kualitas hasil tangkapan.

Jumlah palkah pada kapal pancing tonda adalah 4 buah, 2 buah berukuran kecil dengan panjang $1 \mathrm{~m}$, lebar $80 \mathrm{~cm}$, dan tinggi $80 \mathrm{~cm}$, terdapat pada bagian belakang kapal, 1 buah berukuran sedang dengan panjang $1.50 \mathrm{~m}$, lebar $50 \mathrm{~cm}$ dan tinggi $50 \mathrm{~cm}$, dan 1 buah ukuran besar dengan panjang $2 \mathrm{~m}$, lebar $1 \mathrm{~m}$, dan tinggi $1 \mathrm{~m}$ terdapat pada bagian depan kapal, dapat dilihat pada Gambar 2.

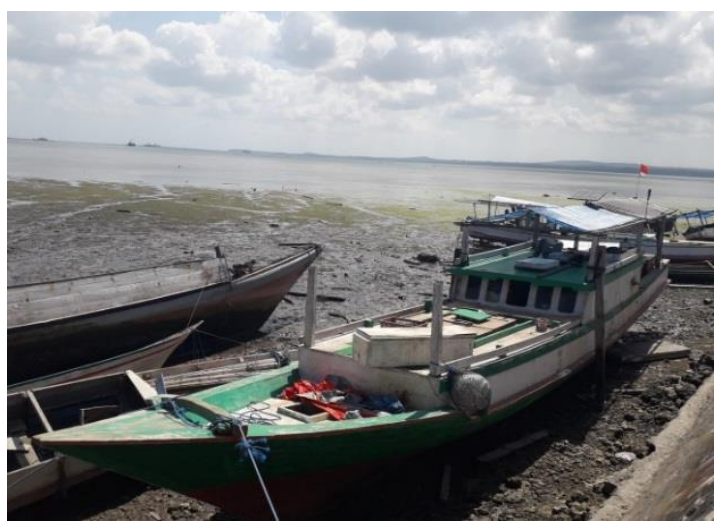

Gambar 2. Kapal pancing tonda

Menentukan ukuran panjang, lebar, dalam, dan tonase kapal harus sesuai dengan metode pengukuran kapal yang telah diatur dalam PM Perhubungan Nomor 8 Tahun 2013 tentang pengukuran kapal. Metode pengukuran dalam negeri memperoleh GT dengan mengalikan faktor yang besarnya 0,25 dengan jumlah volume (V) dari ruangan dibawah geladak ukur dan jumlah volume ruangan di atas geladak yang tertutup. Rumus yang digunakan dalam tonase kotor adalah:

$$
\mathrm{GT}=0,25 \times \mathrm{V}
$$

Diketahui,

$\begin{array}{cc}\text { GT }= & 0,25 \times \mathrm{V} \\ \mathrm{V}= & \mathrm{L} \times \mathrm{B} \times \mathrm{D} \times \mathrm{f} \\ \mathrm{L}= & 17 \mathrm{~m} \\ \mathrm{~B}= & 2,80 \mathrm{~m} \\ \mathrm{D}= & 1 \mathrm{~m} \\ \mathrm{f}= & 0,70\end{array}$

Penyelesaian,

$$
\begin{array}{lc}
\mathrm{V}= & \mathrm{L} \times \mathrm{B} \times \mathrm{D} \times \mathrm{f} \\
\mathrm{V}= & 33,32 \\
\mathrm{GT}= & 8,33
\end{array}
$$

Dari perhitungan di atas dapat diketahui ukuran tonase kotor (GT) untuk kapal pancing tonda di Kepulauan Tanimbar Kota Saumlaki berukuran 8 GT.

Cara penanganan hasil tangkapan yang dilakukan adalah dengan cara penyusunan ke dalam palkah yang sebelumnya sudah berisi es (bungkus). Peranan es untuk menjaga kesegaran ikan dan merupakan langkah penanganan ikan di atas kapal.

Pendaratan hasil tangkapan pancing tonda dimana kapal merapat pada dermaga 
ketika sampai di pelabuhan dilakukan pembongkaran hasil tangkapan, yaitu hasil tangkapan dikeluarkan dari dalam palkah dan dibawa ke pasar Setelah itu dilakukan penyortiran untuk memisahkan ikan berdasarkan jenis (spesies) dan ukuran. Setelah itu di jual ke papalele.

\section{Alat Tangkap}

Pancing tonda pada dasarnya sama dengan pancing biasa yang terdiri dari tali senar, kili-kili, pemberat dan mata pancing. Tali senar yang digunakan adalah bahan monofilament. Tali utama No 1500 , tali pengubung No 1000 dengan panjang 70-115 $\mathrm{m}$, tali cabang dengan No 1000 , panjang tali $20 \mathrm{~cm}$, jarak dari cabang ke cabang lainnya $1.50 \mathrm{~m}$ mata pancing yang digunakan adalah nomor 7 dan 8 terbuat dari baja, kili-kili (swivel) No 05, jarak dari ke mata pancing $10 \mathrm{~m}$, dengan berat pemberat berkisar antara 1-3 kg dan penggulung terbuat dari bahan plastik, kayu dan bambu. Tipe pancing yang digunakan yaitu, pancing tonda berangkai (multipelhandline). Selain itu umpan yang digunakan oleh nelayan pancing tonda ini umumnya mengunakan benang sutra merah dan sutra putih yang dibuat sedemikian bentuk, seperti terlihat pada Gambar 3 .

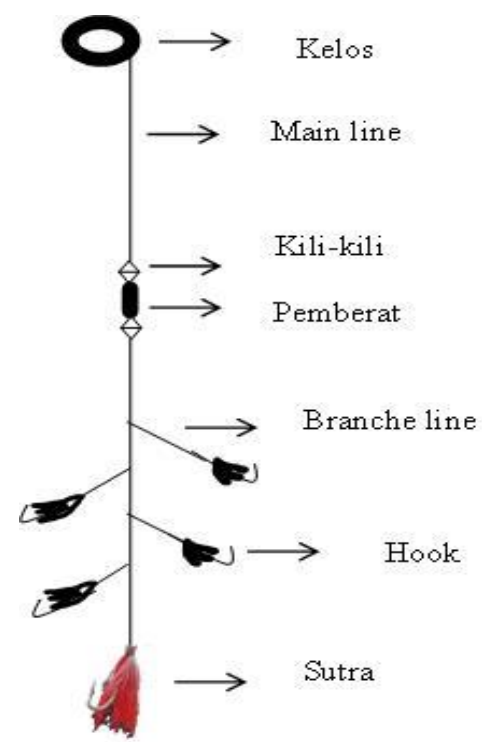

Gambar 3. Desain dan kontruksi pancing tonda.

\section{Daerah Penangkapan Ikan}

Penentuan daerah penangkapan ikan (fishing ground) merupakan salah satu faktor yang menentukan keberhasilan operasi penangkapan ikan. Pada umumnya daerah penangkapan ikan pancing tonda untuk nelayan Kabupaten Kepulauan Tanimbar melakukan penangkapan pada Pulau Selaru, Pulau Yamdena (Olilit Timur), dan pulau Larat (Lamdesar Timur). kegiatan penentuan daerah penangkapan oleh nelayan pancing tonda pada umumnya di sekitar rumpon. Selain itu, nelayan juga mendapat informasi dari sesama nelayan mengenai rumponrumpon yang diketahui potensial untuk melakukan penangkapan disajikan pada Gambar 4.

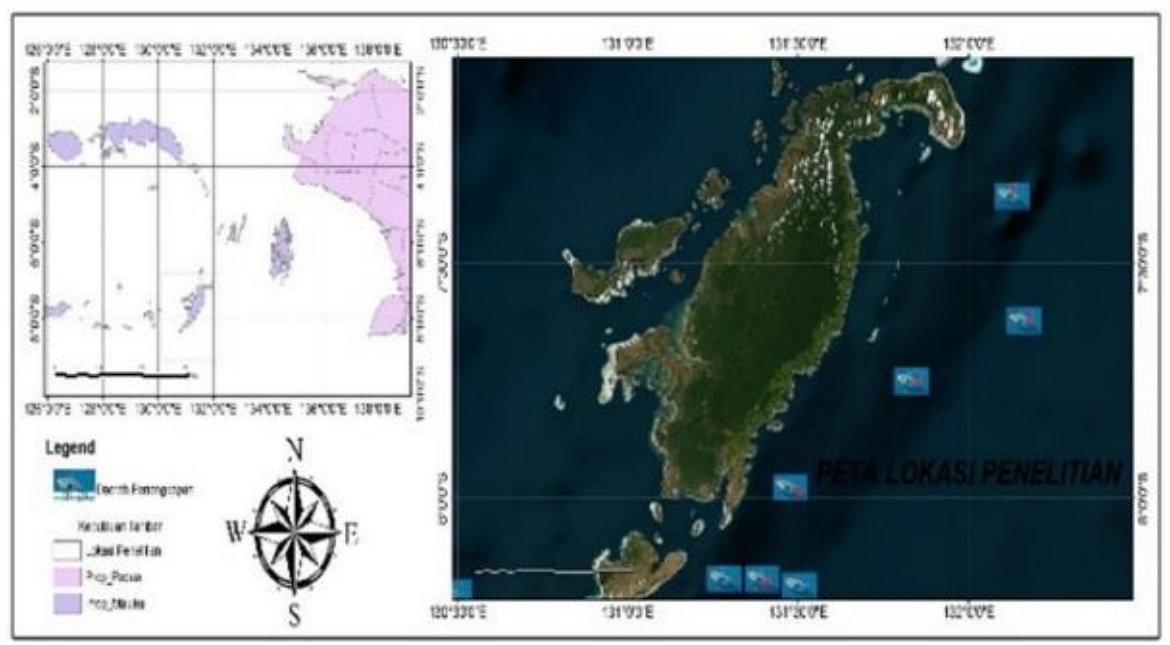

Gambar 4. Daerah penangkapan ikan 
Berdasarkan Gambar 4 menunjukan nelayan sering melakukan penangkapan pada rumpon $4\left(8^{\circ} 44,470^{\prime} \mathrm{S}-131^{\circ} 3,782^{\prime} \mathrm{E}\right)$ dibandingkan rumpon $1,2,3$, dan 5 yang dimana dari lima rumpon tersebut selama 10 trip yang dilakukan oleh nelayan pancing tonda, nelayan melakukan penangkapan sebanyak 6 trip pada rumpon 4 dibandingkan empat rumpon yang hanya masing-masing rumpon tersebut satu kali trip, hal ini menandakan daerah (rumpon 4) tersebut memiliki potensi penangkapan yang sangat tinggi. Hal ini biasa terjadi karena bila dibandingkan dengan lokasi lain, jumlah armada yang bertempat pada lokasi tersebut mencapai 6-7 armada, selain itu berdekatan langsung dengan Australia yang diperkirakan ikan dapat melakukan ruaya ke rumpon tersebut.

\section{Metode Pengoperasian Pancing Tonda}

Kegiatan operasi penangkapan ikan menggunakan pancing tonda pada rumpon. Kapal melakukan satu kali trip selama 4 hari sesuai pembekalan yang dibawa, dalam satu hari dapat melakukan setting dan hauling untuk pancing tonda 13-28 kali. Untuk operasi penangkapan dengan alat tangkap pancing tonda dilakukan dua kali dalam sehari: pertama dilakukan pagi hari sekitar pukul 05:00 WIT dan berakhir paling lama sekitar pukul 09:00 WIT, yang kedua dilakukan sekitar pukul 14:30 WIT dan berakhir sekitar pukul 18:30 WIT.

Pada waktu rumpon ditemukan, yang dilakukan nahkoda kapal yaitu mengurangi kecepatan kapal sedangkan tugas ABK yaitu mempersiapkan alat tangkap pancing tonda yang digunakan untuk operasi penangkapan.

Saat setting kapal tetap berjalan mengelilingi posisi rumpon dengan kecepatan 5-6 knot, sambil mengamati arus dengan memperhatikan posisi rumpon berlabuh. Dalam operasi penangkapan ini kapal menurunkan satu alat tangkap.

Proses hauling merupakan proses pengangkatan hasil tangkapan ke atas kapal, proses ini dilakukan dengan cara menarik pancing secara cepat setelah ikan memakan umpan. Penarikan dilakukan oleh ABK secara cepat dalam melakukan penangkapan.

Nelayan pancing tonda Kabupaten Kepulauan Tanimbar menggunakan umpan palsu yang dipasang pada mata pancing. Proses pembuatan umpan buatan dari benang sutra merah dan putih dengan panjang 5-7 cm, selanjutnya dipasangkan pada mata pancing dan diikat menggunakan tali senar berukuran kecil sampai menutupi bagian atas mata pancing. Menurut Maspeke et al., (2019), bahwa untuk menarik perhatian ikan cakalang yang akan dipancing maka digunakan umpan buatan berwarna merah sedangkan Puspito, (2010) menyatakan ikan calang lebih tertarik kepada warna hijau, merah dan perak. seperti pada Gambar 5.

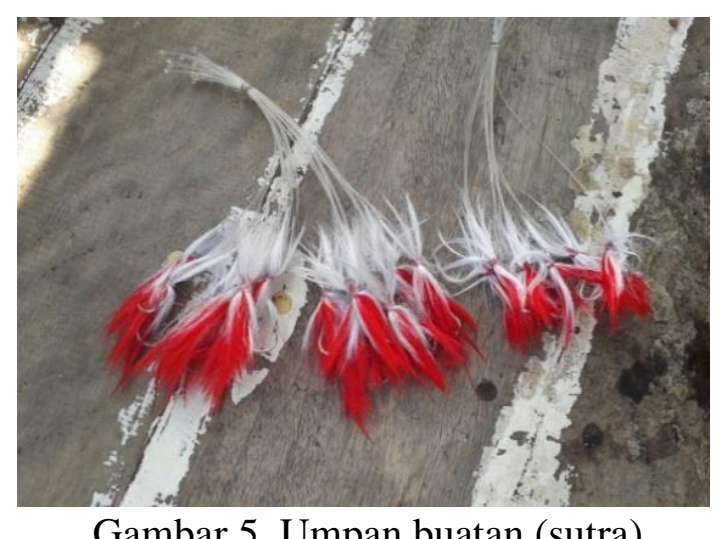

Gambar 5. Umpan buatan (sutra)

Jenis-jenis ikan pelagis yang cenderung sering tertangkap oleh nelayan pancing tonda Kabupaten Kepulauan Tanimbar adalah Cakalang (katsuwonus pelamis) dan Tuna Madidihang (Thunnus albacares), Bahasa Saumlaki (tatihu).

\section{Perbandingan Hasil Tangkapan}

1). Ikan Cakalang (katsuwonus pelamis)

Berdasarkan jumlah dan berat total hasil tangkapan pancing tonda untuk ikan Cakalang (katsuwonus pelamis) pada pagi hari untuk semua trip dapat diketahui jumlah total tertinggi terdapat pada trip pertama sebasar 152 ekor dan terendah pada trip kesembilan sebesar 66 ekor, serta berat total tertinggi pada trip kedelapan sebesar 290.71 $\mathrm{kg}$ dan terendah pada trip kesembilan sebesar $104.4 \mathrm{~kg}$, dan pada sore hari jumlah total ekor tertinggi pada trip keenam sebesar 71 ekor dan terendah pada trip kesepuluh 
sebesar 24 ekor. Serta berat total tertinggi

terendah sebesar trip kesepuluh sebesar pada trip keenam sebesar $139.51 \mathrm{~kg}$ dan $\quad 38.63 \mathrm{~kg}$ dapat dilihat pada Gambar 6 .

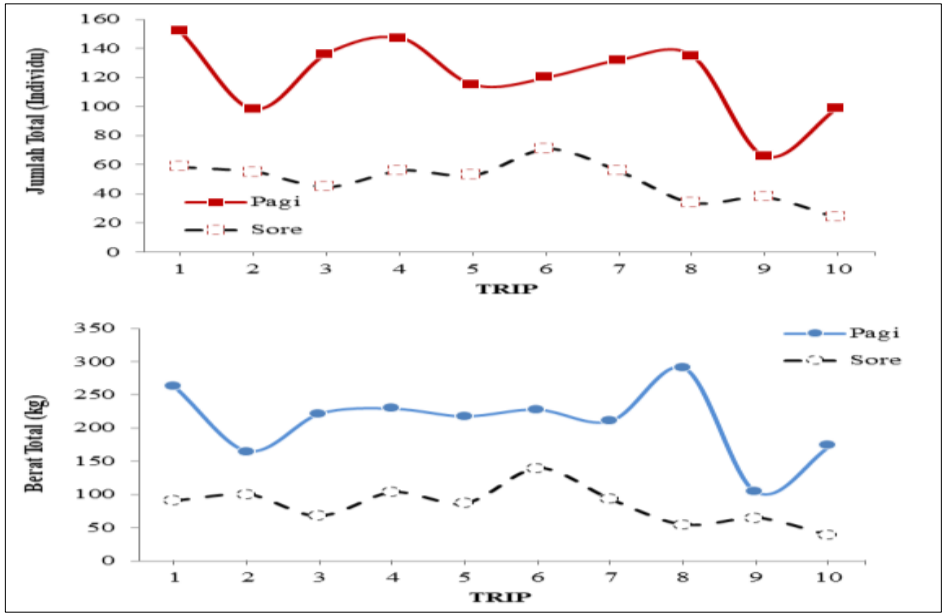

Gambar 6. Jumlah dan berat total ikan cakalang

Berdasarkan hasil tangkapan ikan Cakalang (katsuwonus pelamis) menunjukan hasil tangkapan tertinggi terdapat pada pagi hari dibandingkan dengan sore hari namun memiliki berat yang sama baik pagi hari maupun sore hari. Hal tersebut menunjukkan bahwa penangkapan ikan Cakalang (katsuwonus pelamis) paling bagus dilakukan pada pagi hari dibandingkan pada sore hari, dengan peluang tertangkapnya ikan lebih tinggi untuk pagi hari.

2). Ikan Tuna Madidihang (Thunnus albacares)
Berdasarkan jumlah dan berat total hasil tangkapan pancing tonda untuk ikan Tuna Madidihang (Thunnus albacares) pada pagi hari untuk semua trip dapat diketahui jumlah total tertinggi terdapat pada trip pertama sebasar 170 ekor dan terendah pada trip kesembilan sebesar 52 ekor, serta berat total tertinggi pada trip kedelapan sebesar $320.53 \mathrm{~kg}$ dan terendah pada trip kesembilan sebesar $77.71 \mathrm{~kg}$, dan pada sore hari jumlah total ekor tertingi pada trip kedua sebesar 76 ekor dan terendah pada trip kedelapan sebesar 25 ekor. Serta berat total tertinggi pada trip kedua sebesar $133.16 \mathrm{~kg}$ dan terendah sebesar trip delapan sebesar $42.5 \mathrm{~kg}$ dapat dilihat pada Gambar 7.
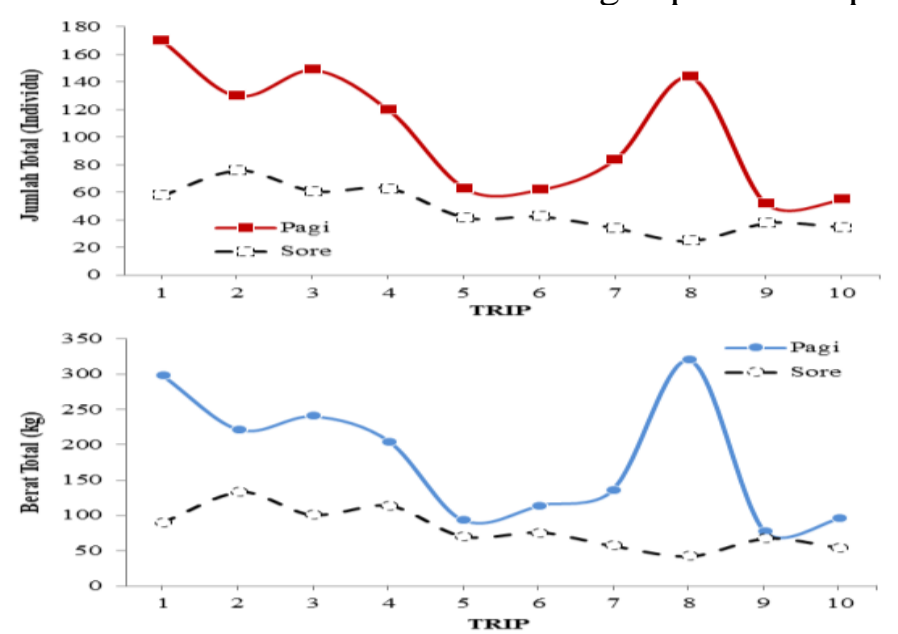

Gambar 7. Jumlah dan berat total ikan tuna madidihang

Berdasarkan hasil tangkapan ikan Tuna Madidihang (Thunnus albacares) menunjukan hasil tangkapan tertinggi terdapat pada pagi hari dibandingkan dengan sore hari namun memiliki berat yang sama baik pagi hari maupun sore hari. Hal tersebut 
menunjukan bahwa penangkapan ikan Tuna Madidihang (Thunnus albacares) paling bagus dilakukan pada pagi hari dibandingkan pada sore hari, dengan peluang tertangkapnya ikan lebih tinggi untuk pagi hari.

Perbandingan produktifitas penangkapan pancing tonda berdasarkan pembagian waktu terlihat bahwa pada pagi hari produktifitas penangkapan pancing tonda lebih tinggi dibandingkan dengan produktifitas penangkapan pada sore hari. Hal ini diduga dipengaruhi oleh tingkah laku makan ikan yang rakus pada saat pagi hari. Hasil ini diperkuat oleh temuan yang menyatakan bahwa pada umumnya ikan albakor aktif makan pada pagi dan berhenti makan menjelang malam hari. Gunarso, (1998) dalam (Barata et al., 2016). Perilaku makan akan ditentukan pada lapar, kenyang atau diantara keadaan kedua kondisi tersebut (Dagrorn et al., 2000 dan Ménard et al., 2007) dalam (Nelwan et al., 2015). Lebih lanjut (Baidhowie et al., 2019) dan (Hidayat et al., 2018) menjelaskan bahwa ikan-ikan karnivora seperti cakalang dan Tuna Madidihang merupakan ikan yang menempati tempat teratas dalam rantai makanan, mengandalkan gerakannya yang cepat dalam air untuk menangkap mangsanya.

Keberadaan rumpon juga berfungsi untuk mencegah jalur migrasi ikan tuna Holland et al (1990) dalam (Hidayat et al., 2016), menyatakan bahwa pergerakan madidihang di perairan hawai berada disekitar rumpon pada siang hari tetapi menjahui rumpon sampai $9,2 \mathrm{~km}$ pada malam hari dan akan kembali pada dini hari keesokan paginya ikan madidihang tertarik dan berasosiasi dengan rumpon bersifat sementara sebelum mereka melanjutkan migrasi ke samudera (Edwards \& Sulak 2006). Sedangkan (Sarianto et al., 2019) menyatakan keberadaan rumpon berdampak positif terhadap peluang keberhasilan penangkapan.

Keadaan lapar terjadi pada saat menjelang pagi hari yang kemudian kenyang dan setelah jam 10 pagi kelompok ikan pelagis besar kembali mencari mangsa hingga menjelang malam hari Josse et al., 1998 dalam (Nelwan et al., 2015). Perilaku tersebut yang diduga menyebabkan kegiatan penangkapan kelompok ikan pelagis besar mengunakan pancing ulur setelah lewat pagi hari membutuhkan durasi waktu yang lebih lama untuk mendapatkan hasil tangkapan selain itu menjelang malam hari kelompok ikan pelagis besar tidak melakukan aktifitas dan berada pada lapisan yang lebih dalam (Josse et al., 1998); (Musyl et al., 2003).

\section{Distribusi Frekuensi Ukuran Panjang Ikan}

Distribusi ukuran panjang ikan sangat ditentukan oleh berbagai faktor, baik faktor internal dari ikan itu sendiri maupun faktor eksternal dari lingkungan adapun ukuran panjang ikan adalah sebagai berikut.

\section{1). Ikan Cakalang \\ Distribusi ukuran panjang (Total} lenght) ikan cakalang pada pagi hari tertangkap mulai dari ukuran panjang total $30 \mathrm{~cm}$ sampai ukuran panjang total $75 \mathrm{~cm}$ dengan ukuran panjang hasil tangkapan dominan pada panjang total $55 \mathrm{~cm}$ sebanyak 377 ekor (31.5\%), sementara ukuran panjang total hasil tangkapan sedikit pada $72 \mathrm{~cm}$ sebanyak 2 ekor $(0.2 \%)$

Disribusi ukuran panjang (Total Lenght) ikan cakalang pada sore hari tertangkap mulai dari ukuran panjang total $30 \mathrm{~cm}$ sampai ukuran panjang total $70 \mathrm{~cm}$ dengan ukuran hasil tangkapan dominan pada panjang total $55 \mathrm{~cm}$ sebanyak 159 ekor (32.4\%) sementara ukuran panjang hasil tangkapan sedikit pada ukuran panjang total $70 \mathrm{~cm}$ sebanyak 1 ekor (0.2\%). Distribusi ukuran panjang ikan cakalang dapat dilihat pada Gambar 8. 


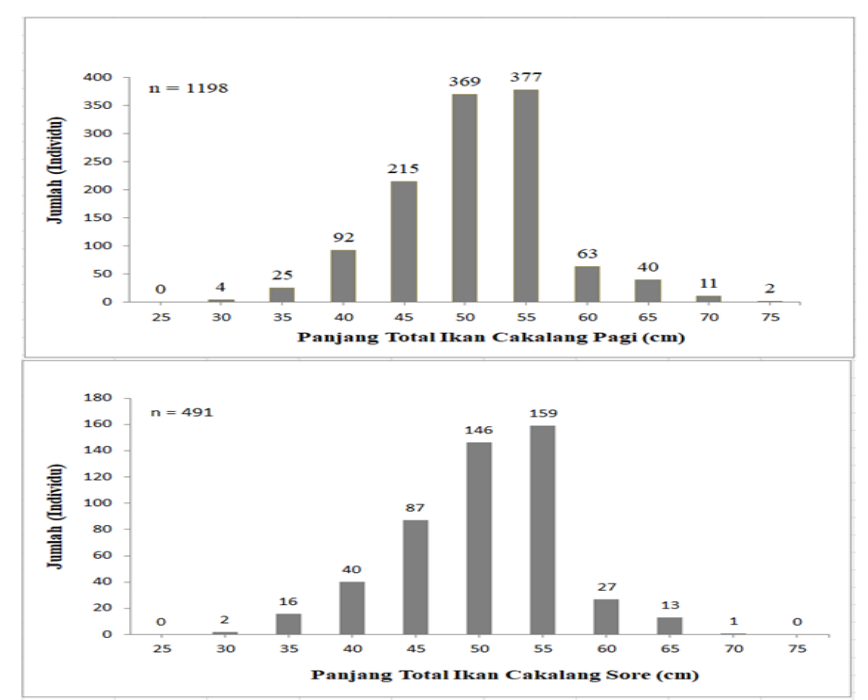

Gambar 8. Ukuran Panjang ikan cakalang pagi dan sore.

Distribusi ukuran ikan cakalang pada kisaran ukuran ini cukup besar/dewasa karena ukuran cakalang pertama kali matang gonad yang tertangkap di perairan sorong adalah 48 (Suhendra and Merta, 1986). Sedangkan (Ashida et al., 2009) menyatakan ukuran pertama kali matang gonad cakalang di samudera bagian tengah dan barat sekitar $40 \mathrm{~cm}$, (Mardlijah and Patria, 2016) panjang pertama kali matang gonad di samudera hindia adalah 42,9 $\mathrm{cm}$. dengan demikian mempertegaskan bahwa ikan-ikan cakalang yang tertangkap dengan alat tangkap pancing tonda sudah dalam kategori dewasa atau layak tangkap.

2). Ikan Tuna Madidihang

Distribusi ukuran panjang (Total tertangkap mulai dari ukuran panjang total $34 \mathrm{~cm}$ sampai ukuran panjang total $74 \mathrm{~cm}$ dengan ukuran panjang hasil tangkapan dominan pada panjang total $54 \mathrm{~cm}$ sebanyak 439 ekor (42.4\%) sementara ukuran panjang hasil tangkapan sedikit pada $69 \mathrm{~cm}$ sebanyak 1 ekor $(0.1 \%)$.

Distribusi ukuran panjang (Total Lenght) ikan tuna madidihan pada sore hari tertangkap mulai dari ukuran panjang total $34 \mathrm{~cm}$ sampai ukuran panjang total $69 \mathrm{~cm}$ dengan ukuran hasil tangkapan dominan pada panjang total $54 \mathrm{~cm}$ sebanyak 162 ekor (39.0\%) sementara ukuran panjang hasil tangkapan sedikit pada ukuran panjang total $34 \mathrm{~cm}$ sebanyak 2 ekor $(0.5 \%)$ dapat dilihat pada Gambar 9.

Lenght) ikan tuna madidihang pada pagi hari

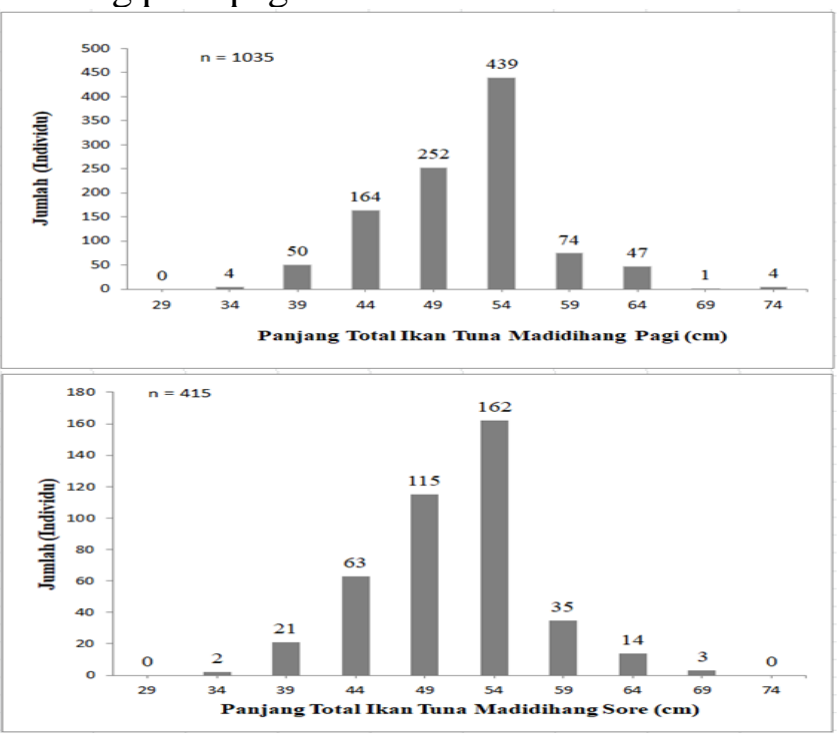

Gambar 9. Ukuran Panjang ikan tuna madidihang pagi dan sore 
Distribusi ukuran ikan tuna madidihang Jika mengacu pada kalisifikasi (Robinson and Simonds, 2006) bahwa tuna madidihang dan tuna mata besar berdasarkan ukuran yakni ukuran $<20 \mathrm{~cm}$ digolongkan sebagai larva, ukuran $20-99 \mathrm{~cm}$ sebagai juvenil atau subdewasa, sedangkan ukuran > $100 \mathrm{~cm}$ dikategorikan ukuran dewasa, dan ukuran pertama kali matang gonad tuna madidihang di Selat Makasar oleh (Kantun et al., 2014). Perbedahan ini diduga berkaitan dengan kondisi lingkungan, ketersediaan makanan, migrasi yang dilakukan oleh ikan tuna dan waktu tangkap (Mallawa and Zainuddin, 2018). Bagi ikan tuna madidihang yang tertangkap termasuk kategori ukuran yang masih muda (Itano, 2001) kerena menurut ukuran panjang pertama kali matang gonad tuna madidihang di Samudera Pasifik Bagian Barat adalah $104.6 \mathrm{~cm}$.

\section{Analisis CPUE}

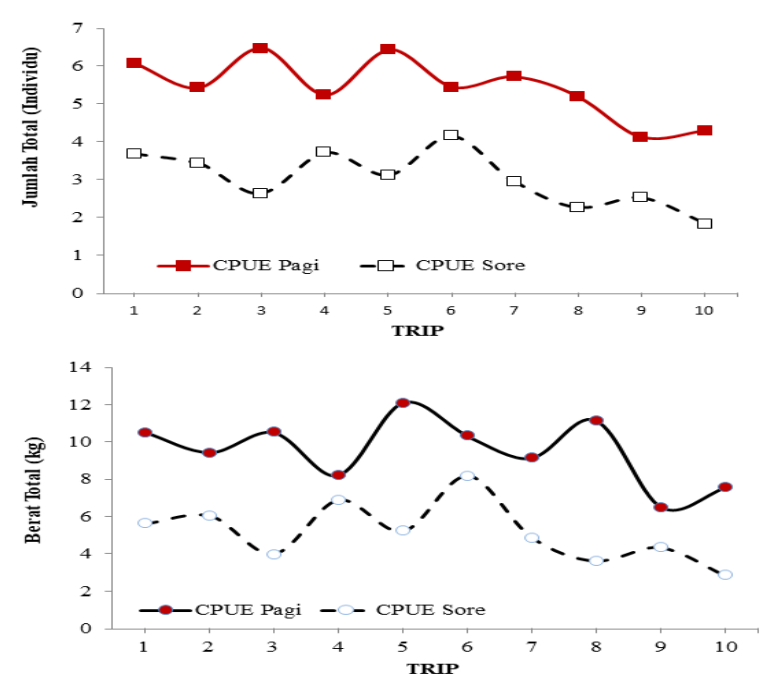

Gambar 10. CPUE jumlah dan berat total ikan cakalang

Berdasarkan Gambar 10 menunjukan terdapat perbedaan CPUE jumlah dan berat total ikan cakalang pada pagi dan sore hari. Nilai CPUE tiap trip terlihat yang paling tinggi adalah pada pagi hari yang dimana trip tertinggi pada pagi hari terdapat pada trip ketiga 7 ekor sementara hasil tangkapan rendah pada trip ke sembilan 4 ekor dan hasil tangkapan pada sore hari trip tertinggi pada trip keenam 4 ekor sementara hasil tangkapan rendah pada sore hari di trip kesepuluh 2 ekor, untuk berat CPUE tertinggi pada pagi hari pada trip kelima $12.11 \mathrm{~kg}$ dan trip terendah pada trip kesembilan $6.53 \mathrm{~kg}$ sementara pada sore hari trip tertinggi terdapat pada trip keenam 8.21 $\mathrm{kg}$ dan renda pada trip kesepuluh $2.87 \mathrm{~kg}$.

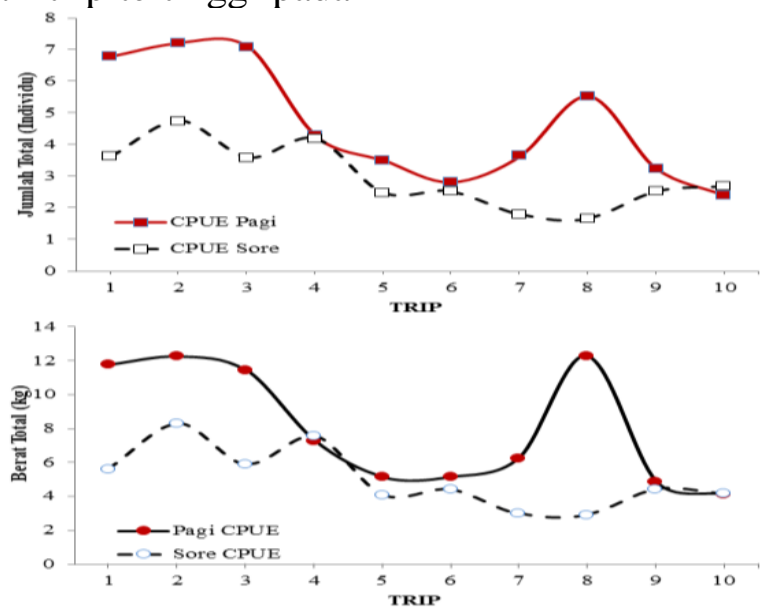

Gambar 11. CPUE Jumlah dan Berat total Ikan Tuna Madidihang 
Berdasarkan Gambar 11 untuk nilai CPUE jumlah dan berat total ikan Tuna madidihang pada pagi dan sore hari, nilai CPUE tiap trip terlihat yang paling tinggi pada pagi hari dibandingkan sore hari yang dimana terdapat pada trip kedua 7 ekor dan terendah pada trip kesepuluh 2 ekor sementara sore CPUE tertinggi pada trip kedua 5 ekor dan rendah pada trip kedelapan 3 ekor. Sementara berat ikan tuna madidihang untuk CPUE tertinggi pada pagi hari terdapat pada trip kedelapan $12.32 \mathrm{~kg}$ dan terendah pada trip kesepuluh $4.15 \mathrm{~kg}$ dan sore hari tetinggi pada trip kedua $8.32 \mathrm{~kg}$ dan terendah kedelapan $2.93 \mathrm{~kg}$.

\section{Analisis Chi-kuadrat}

Tabel 1. Rangkuman Hasil analisis Chi kuadrat Perbandingan hasil tangkapan pancing tonda pada waktu pagi dan sore hari

\begin{tabular}{|c|c|c|c|c|c|}
\hline No & Perbandingan & $\mathrm{X}^{2}$ hitung & $\begin{array}{c}X^{2} \text { Tabel } \\
(0,05)\end{array}$ & $\begin{array}{c}X^{2} \text { Tabel } \\
(0,01)\end{array}$ & Kesimpulan \\
\hline 1 & Ekor cakalang & 26,88 & 16,92 & 21,67 & $\mathrm{H}_{1}$ diterima \\
\hline 2 & Ekor Tuna madidihang & 45,09 & 16,92 & 21,67 & $\mathrm{H}_{1}$ diterima \\
\hline 3 & Berat Cakalang & 80,43 & 16,92 & 21,67 & $\mathrm{H}_{1}$ diterima \\
\hline 4 & Berat Tuna Madidihang & 120,85 & 16,92 & 21,67 & $\mathrm{H}_{1}$ diterima \\
\hline 5 & Ekor Cakalang dan Tuna Madidihang & 57,78 & 16,92 & 21,67 & $\mathrm{H}_{1}$ diterima \\
\hline 6 & Berat Cakalang dan Tuna Madidihang & 172,59 & 16,92 & 21,67 & $\mathrm{H}_{1}$ diterima \\
\hline 7 & CPUE Ekor cakalang & 0,85 & 16,92 & 21,67 & $\mathrm{H}_{1}$ ditolak \\
\hline 8 & CPUE Ekor Tuna madidihang & 2,09 & 16,92 & 21,67 & $\mathrm{H}_{1}$ ditolak \\
\hline 9 & CPUE Berat Cakalang & 16,08 & 16,92 & 21,67 & $\mathrm{H}_{1}$ ditolak \\
\hline 10 & CPUE Berat Tuna Madidihang & 16,58 & 16,92 & 21,67 & $\mathrm{H}_{1}$ ditolak \\
\hline 11 & CPUE Ekor Cakalang dan Tuna Madidihang & 2,07 & 16,92 & 21,67 & $\mathrm{H}_{1}$ ditolak \\
\hline 12 & CPUE Berat Cakalang dan Tuna Madidihang & 29,80 & 16,92 & 21,67 & $\mathrm{H}_{1}$ diterima \\
\hline
\end{tabular}

Berdasarkan kesimpulan hipotesis yang digunakan hasil tangkapan untuk pagi dan sore hari jumlah ekor ikan cakalang, jumlah ekor ikan tuna madidihang, jumlah ekor ikan cakalang dan tuna madidihang. dan berat ikan cakalang, berat ikan tuna madidihang, berat ikan cakalang dan tuna madidihang memiliki nilai $X^{2}$ hitung $>$ $X^{2}$ tabel maka menerima $H_{1}$ dan tolak $H_{0}$, namun pada CPUE, CPUE jumlah ikan cakalang, CPUE jumlah ikan tuna madidihang, CPUE jumlah ikan cakalang dan tuna madidihang dan CPUE berat ikan cakalang, CPUE berat ikan tuna madidihang memiliki nilai $X^{2}$ hitung $<X^{2}$ tabel maka menerima $H_{0}$ atau tolak $H_{1}$ di sebabkan untuk CPUE jumlah dan berat hasil tangkapan pancing tonda dapat menghitung upaya pemancingan pada pagi dan sore hari.
Namun pada CPUE berat ikan cakalang dan tuna madidihang memiliki nilai nilai $X_{\text {hitung }}^{2}>X^{2}$ tabel maka menerima $H_{1}$ dan tolak $H_{0}$.

\section{KESIMPULAN}

Berdasarkan hasil penelitian dapat di ambil kesimpulan sebagai berikut.

1. Kapal pancing tonda yang digunakan berbahan dasar kayu dengan memiliki tiga mesin pada tiap mesin memiliki kekuatan 28 PK, daya muatan kapal berukuran 8 GT. Pancing tonda yang digunakan adalah pancing berangkai (multipellhandline), tali senar yang digunakan berbahan monofilament, serta memiliki pemberat pada alat tangkap, proses pengoperasian menggunakan alat 
bantu (rumpon) dengan mengelilingi posisi rumpon sambil mengamati arus pada daerah penangkapan.

2. Hasil analisis menunjukan bahwa terdapat perbedaan antara jumlah dan berat total hasil tangkapan ikan cakalang (katsuwonus pelamis) dan tuna madidihang (Thunnus albacares) pada pagi dan sore hari dengan mengunakan pancing tonda, yang dimana waktu tangkapan pada pagi hari lebih baik dari pada waktu tangkapan pada sore hari.

\section{DAFTAR PUSATAKA}

Ashida, H., Tanabe, T., Suzuki, N., 2009. Recent progress on reproductive biology of skipjack tuna in the tropical region of the Western and Central Pacific Ocean. Sci. Com. Fifth Regul. Sess. Port Vila Vanuatu.

Baidhowie, L.H., Redjeki, S., Endrawati, H., 2019. Morfometri Dan Komposisi Isi Lambung Katsuwonus pelamis Yang Didaratkan Di Pantai Puger Jember Jawa Timur. J. Mar. Res. 8, 69-74.

Barata, A., Bahtiar, A., Hartaty, H., 2016. Pengaruh perbedaan umpan dan waktu setting rawai tuna terhadap hasil tangkapan tuna di Samudera Hindia. J. Penelit. Perikan. Indones. 17, 133-138.

Hamdi, A.S., Bahruddin, E., 2015. Metode penelitian kuantitatif aplikasi dalam pendidikan. Deepublish.

Hidayat, T., Chodrijah, U., Noegroho, T., 2016. Karakteristik Perikanan Pancing Tonda Di Laut Banda Characteristics Troll Line Fishery In The Banda Sea. J. Penelit. Perikan. Indones. 20, 43-51.

Hidayat, T., Nugroho, T., Chodrijah, U., 2018. Biologi Ikan Tongkol Komo (Euthynnus affinis) Di Laut Jawa. J. Trop. Fish. Manag. 2, 30-36.

Itano, D.G., 2001. The reproductive biology of yellowfin tuna (Thunnus albacares) in Hawaiian waters and the Western Tropical Pacific Ocean, in: Fourteenth Meeting of the
Standing Committee on Tuna and Billfish. pp. 9-16.

Josse, E., Bach, P., Dagorn, L., 1998. Simultaneous observations of tuna movements and their prey by sonic tracking and acoustic surveys. Hydrobiologia 371, 61-69.

Kantun, W., Mallawa, A., Rapi, N.L., 2014. Struktur ukuran dan jumlah tangkapan tuna madidihang menurut waktu penangkapan dan kedalaman di perairan majene selat makassar (structure size and number of catches according from yellow fin (Thunnus albacares) to time and depth in makassar strait). Saintek Perikan. Indones. J. Fish. Sci. Technol. 9, 3948.

Latuconsina, H., 2010. Identifikasi alat penangkapan ikan ramah lingkungan di kawasan konservasi laut Pulau Pombo Provinsi Maluku. Agrikan J. Agribisnis Perikan. 3, 23-30. https://doi.org/10.29239/j.agrikan.3. 2.23-30

Luhur, E.S., Yusuf, R., 2017. Analisis rantai nilai ikan cakalang di Kota Ambon, Maluku. J. Sos. Ekon. Kelaut. Dan Perikan. 12, 93-105.

Mallawa, A., Zainuddin, M., 2018. Population dynamic indicator of the yellowfin tuna Thunnus albacares and its stock condition in the Banda Sea, Indonesia. Aquac. Aquar. Conserv. Legis. 11, 1323-1333.

Mardlijah, S., Patria, M.P., 2016. Biologi reproduksi ikan madidihang (Thunnus albacares Bonnatere 1788) di Teluk Tomini. Bawal Widya Ris. Perikan. Tangkap 4, 27-34.

Martono, N., 2010. Metode penelitian kuantitatif: Analisis Isi dan Analisis Data Sekunder (sampel halaman gratis). RajaGrafindo Persada.

Maspeke, F.I., Puspito, G., Solihin, I., 2019. Kombinasi Ukuran Mata Pancing dan Warna Umpan Tiruan Untuk meningkatkan Hasil Tangkapan Huhate. J. Penelit. Perikan. Indones. 24, 239-251. 
Musyl, M.K., Brill, R.W., Boggs, C.H., Curran, D.S., Kazama, T.K., Seki, M.P., 2003. Vertical movements of bigeye tuna (Thunnus obesus) associated with islands, buoys, and seamounts near the main Hawaiian Islands from archival tagging data. Fish. Oceanogr. 12, 152-169.

Nelwan, A.F., Zainuddin, M., Kurnia, M., 2015. Produktivitas Penangkapan Ikan Pelagis Besar Menggunakan Pancing Ulur Yang Berpangkalan Di Kabupaten Majene (Large Pelagic Fisheries Productivity by Using Handline Based in Majene District). Mar. Fish. J. Mar. Fish. Technol. Manag. 6, 129-142.

Peraturan Pemerintah Nomor 8 Tahun 2013 Tentang pengukuran kapal. Lembar Negara RI Tahun 2013.

Robinson, W.L., Simonds, K., 2006. Management Measures for Pacific Big Eye Tuna and western and Central Pacific Yellow Fin Tuna. Natinal Oceanogr. Atmospheric
Adm. Natl. Mar. Fish. Serv. Pac. Isl. Reg. Off. Honol. Hawaii.

Sarianto, D., 2018. Analisis Daerah Penangkapan Ikan Cakalang (Katsuwonus pelamis) di Sekitar Bacan dan Obi, Halmahera Selatan. SEMAH J. Pengelolaan Sumberd. Perair. 2.

Sarianto, D., Djunaidi, Istrianto, K., 2019. Sebaran Rumpon di Samudera Hindia pada Daerah Penangkapan Purse Seine. J. Airaha 8, 059-066.

Sparre, P., Venema, S.C., 1999. Introduksi pengkajian stok ikan tropis. Buku Man. Pus. Penelit. Dan Pengemb. Perikan. Jkt. 438p.

Sturges, H.A., 1926. The choice of a class interval. J. Am. Stat. Assoc. 21, 6566.

Suhendra, T., Merta, I.G.S., 1986. Hubungan Panjang Berat, Tingkat Kematangan Gonad dan Fekunditas Ikan Cakalang Katsuwonus pelamis (Linnaeus) di Perairan Sorong. J. Penelit. Perikan. Laut 34, 11-19. 